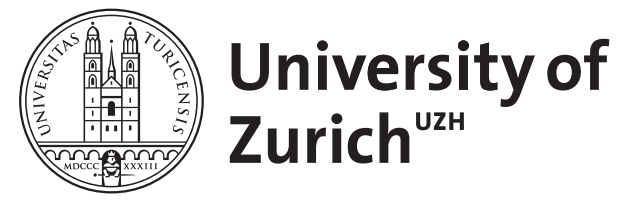

Maintaining and promoting mobility and functional independence in older adults

Martin, Mike ; Kressig, R W ; Röcke, C

DOI: https://doi.org/10.1159/000322193

Posted at the Zurich Open Repository and Archive, University of Zurich ZORA URL: https://doi.org/10.5167/uzh-51694

Journal Article

Published Version

Originally published at:

Martin, Mike; Kressig, R W; Röcke, C (2011). Maintaining and promoting mobility and functional independence in older adults. Gerontology, 57(3):237-238.

DOI: https://doi.org/10.1159/000322193 


\title{
Editorial: Maintaining and Promoting Mobility and Functional Independence in Older Adults
}

\author{
Mike Martin $^{a}$ Reto W. Kressig ${ }^{c}$ Christina Röcke ${ }^{b}$ \\ ${ }^{a}$ Gerontopsychology, Department of Psychology, and ${ }^{b}$ International Normal Aging and Plasticity Imaging Center, \\ University of Zurich, Zurich, and ${ }^{C}$ Department of Acute Geriatrics, Basel University Hospital, Basel, Switzerland
}

This special section on maintaining and promoting mobility and functional independence in old age is the first in Gerontology to bridge the gap between clinical and behavioral perspectives on central aging phenomena. Whereas clinical perspectives are typically concerned with early detection, assessment or rehabilitation of impairments, behavioral perspectives are typically more focused on normal aging defined as aging without chronic illnesses [1]. Both perspectives have long and well-established research traditions that have produced important improvements in differential assessments of individuals' resources and new insights into the potentials of aging, prevention possibilities and adaptive capacities. On the one hand, this is illustrated by numerous contributions in this journal alone demonstrating the effectiveness of clinical interventions in reducing the incidence and effects of falls, depression, dementia and many other impairments. On the other hand, contributions using longitudinal data to examine normal development have improved our understanding of the possible ranges of normal development and factors contributing to optimal development and neural as well as behavioral plasticity.

From our own experience of the productivity of applying models of normal aging to clinical problems, we believe that bridging the gap between these mostly independent research traditions could lead to innovative clinical and behavioral research. For example, the idea of using dual tasks combining cognitive and motor demands to

\section{KARGER}

Fax +4161306 1234

E-Mail karger@karger.ch

www.karger.com
(C) 2010 S. Karger AG, Basel

0304-324X/11/0573-0237\$38.00/0

Accessible online at:

www.karger.com/ger understand the dedifferentiation of abilities with increasing age [2] can be fruitfully adapted to improve the assessment of abilities in individuals with motor and/or cognitive impairments. In our laboratories, we now use this approach with an adapted dual-task paradigm $[3,4]$ to assess the ability of dual-tasking in impaired populations. This is based on the assumption from normal aging research that even with impairments, it is clinically helpful to determine the abilities of individuals. Instead of focusing on either motor or cognitive impairments, we can now also focus on and assess the ability of an individual to 'pay' with some motor resources for maintaining cognition, and vice versa, i.e. how individuals manage to maintain dual-tasking abilities by flexible 'withdrawal' and reallocation of motor or cognitive resources. This also helps to resolve the contradictory findings of studies reporting a stable and general preference for either protecting motor functioning [5] or cognitive functioning [6] in clinical populations. In addition, a dual-tasking approach can help to identify fruitful venues for the development and use of assistive technology for older individuals [7]. Thus, in this first 'gap-bridging' special section, we have invited authors studying the interactions of motor abilities with cognitive functioning in old age, or complex everyday motor behaviors that are known to be related to cognitive functions in the clinical and behavioral domains, to present their perspectives on the development of cognitive and motor abilities in old age. 


\section{Brief Overview of Special Section Contributions}

Schäfer and Schumacher [8] provide an overview of two types of studies on the interplay between cognition and motor functioning in healthy adults: dual-task studies and training studies focusing on the effect of fitness training on cognitive performance. In addition, they describe an ongoing collaborative intervention study with combined cognitive and fitness training in older adults, in which training effects will be examined both at the behavioral and neural levels.

Granacher et al. [9] consider multitasking situations and examine age-related differences in cognitive and motor interference effects on both static and dynamic postural control due to simultaneous task performance in healthy young compared to healthy older adults. Their findings indicate that static (e.g. standing) and dynamic (e.g. walking) measures of postural control are relatively independent of one another and may, hence, profit from complementary intervention and training effects.

With a specific focus on possible intervention regimens, Bridenbaugh and Kressig [3] focus on the association between cognition and one of the strongest risk factors for falls, gait impairment. In their paper, they provide an overview of their research on spatial-temporal gait analysis at the Basel Mobility Center. Using a dual-task paradigm allows them to identify clinically significant gait changes in order to detect gait disorders early enough for interventions to decrease fall risk.

Thom and Clare [10] advocate a combined exercise and cognition-focused intervention approach for individuals suffering from dementia, highlighting key parameters to be considered for a combined intervention to be effective, and also pointing out possibilities and limitations of integrating such additional interventions into the regular treatment of demented adults.

Büla et al. [11] focus on older adults' cognitions about their motor abilities, namely impaired balance confidence as a central fall-related risk factor. They review interventions to improve balance confidence in older community-dwelling adults and show that exercise appears to be a key component of successful interventions.

Cress et al. [12] examine everyday motor behaviors in a population with lower levels of cognitive functioning. They report a cross-sectional study investigating the relationship between living environment and mobility in older adults. Results indicate that adults living in a retirement community compared to community-dwelling adults are less mobile and have greater functional impairments, suggesting that interventions are needed to increase mobility and physical activity for those adults in assisted-living communities with a lower level of cognitive abilities. In these populations in which motor behaviors are more closely related to (decreased) cognitive abilities, increasing motor activities may help to maintain cognitive functions.

Together, the authors highlight the importance and potential of a balanced link between motor function and cognition while aging. Bridging the gap between clinical and behavioral research on the interaction between motor abilities and cognitive functioning in old age allows an earlier detection of functional motor and/or cognitive impairments and, at the same time, opens up new perspectives for combined prevention and treatment strategies in the important geriatric-gerontological fields of falls and dementia.

\section{References}

1 Martin M, Kliegel M: Psychologische Grundlagen der Gerontologie, ed 3. Stuttgart, Kohlhammer, 2010.

2 Lindenberger U, Baltes PB: Sensory functioning and intelligence in old age: a strong connection. Psychol Aging 1994;9:339-355.

3 Bridenbaugh SA, Kressig RW: Laboratory review: the role of gait analysis in seniors' mobility and fall prevention. Gerontology 2011; 57:256-264.

4 Theill N, Schumacher V, Martin M, Bridenbaugh S, Kressig R: Measuring dual gait and cognitive performance in healthy vs cognitively impaired older adults: the Basel Dual Task Impairment paradigm. J Am Geriatr Soc 2010 , in preparation.
5 Li K, Lindenberger U, Freund AM, Baltes PB: Walking while memorizing: age-related differences in compensatory behavior. Psychol Sci 2001;12:230-237.

6 Lundin-Olsson L, Nyberg L, Gustafson Y: 'Stops walking when talking' as a predictor of falls in elderly people. Lancet 1997;349:617.

7 Lindenberger U, Lövdén M, Schellenbach M, Li SC, Krüger A: Psychological principles of successful aging technologies: a mini-review. Gerontology 2008;54:59-68.

8 Schaefer S, Schumacher V: The interplay between cognitive and motor functioning in healthy older adults: findings from dual-task studies and suggestions for intervention. Gerontology 2011;57:239-246.
9 Granacher U, Bridenbaugh SA, Muehlbauer T, Wehrle A, Kressig RW: Age-related effects on postural control under multi-task conditions. Gerontology 2011;57:247-255.

10 Thom JM, Clare L: Rationale for combined exercise and cognition-focused interventions to improve functional independence in people with dementia. Gerontology 2011;57: 265-275.

11 Büla CJ, Monod S, Hoskovec C, Rochat S: Interventions aiming at balance confidence improvement in older adults: an updated review. Gerontology 2011;57:276-286.

12 Cress ME, Orini S, Kinsler L: Living environment and mobility of older adults. Gerontology 2011;57:287-294. 